\title{
New Media Ecology and Theoretical Foundations for Nonfiction Digital Narrative Creative Practice
}

Citation for published version (APA):

Basaraba, N., Arnds, P., Edmond, J., \& Conlan, O. (2021). New Media Ecology and Theoretical Foundations for Nonfiction Digital Narrative Creative Practice. Narrative, 29(3), 374-395. https://doi.org/10.1353/nar.2021.0017

Document status and date:

Published: 01/10/2021

DOI:

10.1353/nar.2021.0017

Document Version:

Publisher's PDF, also known as Version of record

Document license:

Taverne

Please check the document version of this publication:

- A submitted manuscript is the version of the article upon submission and before peer-review. There can be important differences between the submitted version and the official published version of record.

People interested in the research are advised to contact the author for the final version of the publication, or visit the DOI to the publisher's website.

- The final author version and the galley proof are versions of the publication after peer review.

- The final published version features the final layout of the paper including the volume, issue and page numbers.

Link to publication

\footnotetext{
General rights rights.

- You may freely distribute the URL identifying the publication in the public portal. please follow below link for the End User Agreement:

www.umlib.nl/taverne-license

Take down policy

If you believe that this document breaches copyright please contact us at:

repository@maastrichtuniversity.nl

providing details and we will investigate your claim.
}

Copyright and moral rights for the publications made accessible in the public portal are retained by the authors and/or other copyright owners and it is a condition of accessing publications that users recognise and abide by the legal requirements associated with these

- Users may download and print one copy of any publication from the public portal for the purpose of private study or research.

- You may not further distribute the material or use it for any profit-making activity or commercial gain

If the publication is distributed under the terms of Article $25 \mathrm{fa}$ of the Dutch Copyright Act, indicated by the "Taverne" license above, 


\section{PROJECT MUSE*}

New Media Ecology and Theoretical Foundations for Nonfiction

Digital Narrative Creative Practice

Nicole Basaraba, Peter Arnds, Jennifer Edmond, Owen Conlan

Narrative, Volume 29, Number 3, October 2021, pp. 374-395 (Article)

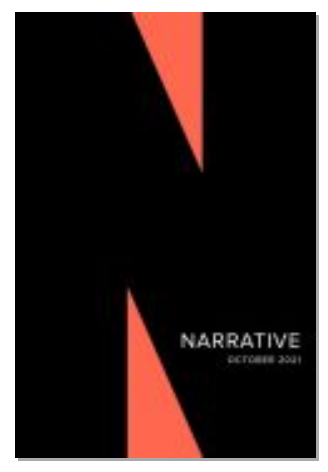

Published by The Ohio State University Press

DOI: https://doi.org/10.1353/nar.2021.0017

$\Rightarrow$ For additional information about this article https://muse.jhu.edu/article/809285 


\title{
Nicole Basaraba, Peter Arnds, Jennifer Edmond, and Owen Conlan
}

\section{New Media Ecology and Theoretical Foundations for Nonfiction Digital Narrative Creative Practice}

\begin{abstract}
Digital storytelling techniques and persuasive communications are becoming increasingly intertwined and realized in cultural discourses such as cultural heritage, environmental activism, and politics. Rhetorical theory has grounded and influenced communication practice since the age of oration, and as society is increasingly undergoing new mediatization, digital rhetorical theory can be reexamined and applied to nonfiction digital narratives for improved practice. Narratology provides key theoretical foundations that are braided into digital rhetoric for application to digital nonfiction narratives. This article highlights how new media has changed the impacts of the modes of persuasion (ethos, pathos, logos, and kairos) on today's multimedia-consuming audiences and how the classical rhetorical canons (invention, arrangement, style, delivery, and memory) can be reframed and updated by incorporating narrative theory to aid creators of new nonfiction digital narratives across different genres.
\end{abstract}

KEYWORDS: digital narrative, nonfiction, digital rhetoric, new media, theory, creative industries

\begin{abstract}
Nicole Basaraba is a postdoctoral researcher at Maastricht University, The Netherlands, and she holds a $\mathrm{PhD}$ from Trinity College Dublin, Ireland. Her transdisciplinary research looks at how participatory digital culture impacts nonfiction, transmedia storytelling practices with a focus on cultural heritage tourism contexts.
\end{abstract}

Peter Arnds is Associate Professor and Director of the MPhil in Comparative Literature at Trinity College Dublin. He is a Fellow of Trinity College and was recently elected to membership of Academia Europaea. He is the faculty mentor to the Trinity Journal of Literary Translation and has published over fifty journal articles and several book chapters and academic monographs.

Jennifer Edmond is Associate Professor in the School of Language, Literatures, and Cultural Studies at Trinity College Dublin. Her research expertise focuses on the impact of technology on interdisciplinary humanities research. She is a contributor to many large-scale European projects including DARIAH, CENDARI, PARTHENOS, and eCloud.

Owen Conlan is Associate Professor of Computer Science and Statistics at Trinity College Dublin and is the Theme Leader of "Personalising the User Experience" in the ADAPT Centre. His research interests also include digital humanities projects and interdisciplinary research with a computer science component. 


\section{Introduction}

To date, most digital narrative forms are fictional, but as new media technologies continue to develop, nonfiction digital narratives are increasingly emerging in topical areas such as cultural heritage (museums, galleries, libraries, and archives), education and gamification (for school-aged children), and activism (climate change and conservation movements). For example, 3D model tours like Virtual Rome (a virtual model of the ancient city), transmedia stories such as Red Nose Day (2016) (a broadcasted series of comedy sketches to fundraise for charity), and interactive documentaries like The Last Generation (2018) (in which journalists show the effects of climate change in the Marshall Islands) all make use of digital media to tell nonfictional stories. These dynamic and new narrative genres call for the reexamination of how rhetoric is created and received within the context of an increasingly digital media society. Theories from media studies and narratology are used to create a bridge between the composition of persuasive nonfiction communications and narratives. As new genres of digital narrative continue to emerge, scholars have begun using new terminology to specify the particularities of their research focus. The umbrella term "interactive digital narrative" (IDN) is used to describe scholarly work in the areas of intelligent narrative technologies, interactive drama, interactive storytelling, and narrative games (Monfort $\mathrm{x}$ ). The term "narrative" is often used interchangeably with "story," but the concept of narrative allows researchers to specify the object of their discipline and isolate the features relevant to their inquiry (Ryan, "Toward" 28). IDN decouples narrative from specific media, allowing for experimentation in new forms (Koenitz 178), and the object of focus is new digital forms of creating narrative. Thus, Herman's definition of narrative as a "forgiving, flexible cognitive frame for constructing, communicating, and reconstructing mentally projected worlds" (49) applies to different genres of IDN and allows for increased flexibility and transdisciplinary critical discourse.

Previous research on emerging forms of IDNs has largely focused on fictional genres such as interactive cinema, transmedia, and video games. To address the nonlinear dramatic structure afforded by computers, Brenda Laurel applied Aristotle's Poetics to computational narratives in fictional dramas of tragedy, comedy, and melodrama. However, many, if not most, nonfiction IDNs are designed with a particular rhetorical purpose (e.g., to elicit empathy or to educate); thus, Aristotle's Rhetoric provides a foundation for the future development of nonfiction IDNs. Developed in the fourth century BC, Aristotle's Rhetoric provides principles that can be modified, updated, and applied to digital narratives of the twenty-first century. Classical rhetoric was associated with oral speeches for civic persuasion, but as different media of communication developed, rhetorical theory was subdivided into visual, digital, and procedural rhetorics. Rhetorical theory "is a situated and applied art, it generates principles, not rules. The difference is significant: principles are always interpreted and adjusted for situations (and rarely survive in pure form); rules circumscribe absolute boundaries" (Porter and Sullivan). Applying rhetoric to IDN creation can help nonfiction creators release new works with a higher degree of confidence that the desired communication goals will be achieved. A key impact on digital rhetoric in today's 
society is the fact that new media audiences participate in the production process and, thus, invention becomes a work in progress (Pfister). IDNs aim to permeate the fourth wall where users enter the narrative and participate in its unfolding (Koenitz et al., "Introduction" 1). This active participation is known as dramatic agency, which is "the satisfying power to take meaningful action and see the results of our decisions and choices" (Murray 126). For example, users can create or influence a dramatic storyline by assuming the role of a character in a fictional virtual world, issuing commands to computer-controlled characters, or directly manipulating the fictional world state (Riedl and Bulitko 67). As experimentation is common and growing across the creative industries, this paper discusses how new media has changed how the modes of persuasion (ethos, pathos, logos, and kairos) are used to persuade today's multimedia-consuming audiences and provide an overview of the current media ecology in the context of digital narrative. Due to the changing techniques of digital narrative communication, digital rhetoric and narrative theory are merged and the classical rhetorical canons are reframed to provide a theoretical foundation to aid creative practice in the future development of nonfiction IDNs.

\section{Rhetoric in Nonfiction Digital Narratives}

Growing areas of nonfiction digital narratives appear in the context of cultural heritage, education, and civic activism, and two genres commonly used to communicate these nonfiction narratives are interactive documentaries (iDocs) and serious games. These two genres fall under the umbrella of "interactive digital narratives" because they provide users with dramatic agency to make narrative choices and influence what the emergent narrative outcome is through their interactions. iDocs and serious games exemplify how digital media has evolved narrative techniques and impacted the audience's reception of rhetoric in nonfiction genres. Here iDocs and serious games are referred to as two nonfiction genres of IDNs. As Nielsen, Phelan, and Walsh clarify, "Generic frameworks signal the global status of a text as either fiction, nonfiction, or ambiguous" ("Fictionality" 105; emphasis original). For example, the terms "documentary" and "serious" act as global signals to the overarching rhetorical intent of these two genres to communicate factual or real (i.e., nonfiction) events. However, it is noted that communicative techniques employed within these genres may include instances of "fictionality", defined as a rhetorical quality that involves "the inventing of possibilities rather than reporting actualities, and one that functions as a distinct communicative resource" ("Fictionality" 105; emphasis original). In other words, these nonfiction IDN genres can include local uses of fictionality, although their primary communicative intent is focused on real events, issues, or topics.

Firstly, the interactive documentary (iDoc) is a genre that has an origin, definition, and scope that are difficult to pinpoint in the literature. In a general sense, iDocs are "any project that starts with an intention to document the 'real' and that uses digital interactive technology to realize this intention" (Aston and Gaudenzi 125). The fluidity of this newer IDN genre stems from the multiple different terms used to describe different works, the common appearance of remediated genre conventions 
of linear documentary film, and its study falling across multiple fields such as cinema, interaction, videogames, and video art (Almeida and Alvelos 123-24). Key genre requirements for iDocs are moving images, full-screen viewing, and audio (124-25). Many iDocs are distributed on the web (i.e., webdocs), but they are also built on a variety of digital platforms including DVDs, mobile phones, GPS devices, and gallery installations (126). Aston and Gaudenzi summarize different modes of interactivity in iDocs, including the conversational, hypertext, experiential, and participatory modes (126-28). The conversational mode uses 3D worlds to create an apparently seamless interaction with the user, who navigates freely as seen in some video games; the hypertext mode where assets within a closed video archive place users in an exploratory role enacted by selecting preexisting options; the participative mode (i.e., collab-docs or participatory-docs) allows the user to be involved during the production process or during launch and distribution, such as by editing or shooting footage; and the experiential mode invites the user to experience a hybrid space, often using GPS to bring digital content into the physical space.

Interactive documentaries frequently aspire to expand documentary's political role to provide new ways of engaging with social issues, participation, and citizenship, and they are shaped by cultures and possibilities of digital media (Nash 9). Documentary has the ability to enhance public knowledge, to provide citizens with informational resources to aid decision-making, and to create potential platforms for action and participation (Nash 10-11). An affordance of iDocs is that they can "present multiple points of view-whether from the perspective of a single authorial voice or from the perspective of a community of authors working collaboratively around a common theme-and they can be used to present contested points of view, allowing users to come to their own conclusions" (Aston and Gaudenzi 133).

Commonly cited examples of iDocs are Gaza/Sderot (2008), Bear 71 (2012), Hollow (2013), and Fort McMoney (2013). The rhetorical functions of iDocs are seen in the example of Fort McMoney - a "documentary game" that addresses the social, economic, and environmental impacts of Canada's oil sands industry in Fort McMurray, Alberta, to encourage collective debate and decision-making (Nash 23). Fort McMoney (2013) presented audio-visual information, fostered informed debates through weekly forums, and contributed to the formation of public opinion through various polls and collective decision-making through weekly referenda (Nash 15). The documentary game is called Fort McMoney, although the city it is set in and engaging public debate about is Fort McMurray: the rhetorical technique of fictionality (Nielsen, Phelan, and Walsh, "Ten Theses") is used here as an overarching argument or metaphor that the city is money because of the economic impacts of oil sands located in the area. Fort McMoney emphasizes the value of collective engagement and shared experience so that players understand different perspectives on the issue and can form a collective conscience (Nash 16). The documentary did inspire participatory action; however, the ensuing digital debates focused on pro-environment stances and may have alienated those with a pro-industry perspective, while the social media (i.e., Twitter) conversations focused on the novelty of the digital media game rather than on the oil sands (Nash 20-21). Therefore, Fort McMoney inspired different types of participation and interest in the message as well as the new narrative form. As 
iDocs continue to be developed, a number of creators are increasingly inviting usergenerated content and creative audience communities to participate in funding the projects (i.e., crowdfunding) (O'Flynn 142). For example, transmedia documentaries that rely on curation and collaboration of user-generated content are different than those where the design is based on highly structured and authored content systems. Participatory iDocs are "increasingly processual in that they can be designed as ongoing projects inviting the submission of participant-generated content" (O'Flynn 149). As a genre, iDocs can stimulate multi-perspective conversations and have the potential to persuade the public or encourage participatory civic action through nonfiction narratives.

Moving on to the genre of "serious games," this term has been grouped together and used interchangeably with the concepts of "gamification," "game-based learning," "pervasive games," and "alternate reality games" (Xu, Buhalis, and Weber 245-46). Serious games apply gaming principles to a variety of nonfiction or "serious" topics such as business, health, education, and archaeology, as well as cultural heritage and tourism. Serious games exist in forms including mobile applications, web-based solutions, computer games, and mixed reality games that combine real and virtual interactions (Anderson et al. 2). Andreoli et al. note that serious games are developed for training and educational purposes and gamification uses game design elements to engage users and motivate desired behaviors (3). Similarly, serious games may include instances of fictionality in the form of avatars (i.e., characters) and other game mechanics, such as role-playing, reenactment, or abstract animations of reconstructed environments (Mortara et al. 320). In the context of cultural heritage gamification, Anderson et al. classify the differences between game-like applications into "prototypes and demonstrators," "virtual museums," and "commercial historical games," all of which achieve different rhetorical purposes. Firstly, "prototypes and demonstrators" focus on digital visualizations of reconstructed archaeological sites, including Rome in 320 AD (in Rome Reborn), ancient Pompeii before the eruption of Mount Vesuvius in $79 \mathrm{AD}$, and the reconstruction of the sculptural decorations on the Parthenon in $437 \mathrm{BC}$ (Anderson et al. 2-3). These examples demonstrate what life was like in these times in history, but provide little information or narrative beyond the visualization, and little user agency.

Secondly, "virtual museums" have incorporated digital interactivity and gaming elements to showcase and engage the public with history and archives. The major digital developments in museum practices are summarized by Kidd, who explains that contemporary museums are: engaging in transmedia because they exhibit their materials across multiple media; using social media to converse with their audiences and shifting the dynamic of trust as audiences become authors by producing user-generated content; incorporating personal narratives in some exhibitions; and creating interactive digital displays that may include gaming aspects within museums and online. Virtual museums employ a variety of technologies such as imaging technologies, Web3D, virtual reality, augmented reality, haptics (involving navigation through physical touch), and the use of handheld devices (e.g., cell phones, personal digital assistants, and tablets) (Styliani 520-24). For example, two digital exhibitions for learning within museums are the mARCHive and Imago Bononiae. The mAR- 
CHive is a 360-degree video exhibition for the 80,000 records of Museum Victoria in Australia, which allows users to engage in emergent narratives organized by theme (Kenderdine). Imago Bononiae is a 3D real-time application that is projected onto a wall or screen and allows people to use physical body movements (i.e., haptics) to change the displayed content regarding the reconstruction of Bologna, Italy (Fanini and Pagano). These immersive experiences in museums allow visitors to see and interact with more content in digital forms that may not be available for physical display.

Finally, "commercial historical games" communicate significantly more educational information through a documentary-like experience mixed with player agency in gameplay interactions (Anderson et al. 2-3). Locative media heritage games such as The Voices of Oakland Cemetery, Riot 1831 at Nottingham Castle, and Viking Ghost Hunt are often designed to engage and educate tourists (Haahr 114). For example, The Voices of Oakland Cemetery provided auditory and augmented reality content to introduce virtual or in-person visitors to the history, architecture, and dramatized personal stories of notable people buried in the cemetery (Dow et al.); Riot 1831 at Nottingham Castle used augmented reality to add interpretive value to the heritage of the 1831 riot at the castle, creating opportunities for deepening engagement via multiple narrative perspectives; and Viking Ghost Hunt engaged the player in local Viking history between the years 800 and 1169 through a narrative-led location-aware ghost-hunting game based in Dublin, Ireland (Paterson et al. 65). These projects have gamified and narrativized history related to specific locations to engage players, who may secondarily learn something as a result of interacting with the locative media applications. The advantages of locative-based games are that they make use of multimodality, they are immersive, and they focus on creating a narrative. However, they often remediate the conventions of fictional narratives by focusing on presenting characters (i.e., avatars) in a storyworld. Another limitation of being location-based is that they cannot be fully experienced unless the user visits the historical sites and has access to the technologies or media (e.g., mobile devices) that are required to deliver the experience. McKercher and Du Cros found that most tourists participate for recreational and pleasure reasons rather than for deep learning experiences, and they recommend that cultural tourism content be presented in an easily consumable and enjoyable manner that may contain elements of learning but should firstly entertain (56-57).

Therefore, iDocs and serious games exemplify new methods of creating narratives in different media and have differing impacts on their audiences, such as inspiring civic action or educating visitors. As these new genres continue to develop, revisions and expansions of digital rhetorical theory can aid future creators in understanding how new interactive digital narrative forms can be used to enhance desired communicative effects on audiences. This can be achieved by first considering how the modes of persuasion have evolved in the context of digital narratives, as detailed in the following section. This analysis is then followed by the presentation of a rhetorical theory-based framework that aims to be of practical use for future nonfiction IDN creators. 


\section{Merging Digital Rhetoric and Narrative Theory}

The current state of digital rhetoric stands to benefit from critical engagement with existing theories and methods from other fields (Eyman). Thus, media ecology and narrative studies are merged here into digital rhetoric to provide new insight into the creative practice of nonfiction IDNs. As one of the first to write a review of digital rhetorical scholarship, Zappen called for a move toward a unified theory based on the extension and transformation of traditional rhetoric (319). Digital rhetoric is "an amalgam of more-or-less discrete components" such as self-expression and collaboration, the affordances and constraints of digital media, and the formation of identities and communities (Zappen 323). Reviewing the current state of digital rhetoric, Boyle, Brown, and Ceraso argue that "to practice digital rhetoric is to participate in a transductive process of information through a series of incorporations that involve culture, technology, and biology along with many more registers" (258). Thus, digital rhetoric is a transdisciplinary theory that can be applied to any nonfiction genre of IDN. Narrative and rhetoric have been examined by theorists separately, but have been integrated in three main areas. Firstly, in rhetorical narratology, developed within literary criticism and analysis; secondly, in rhetorical discourse examining narratives within communications; and finally, in rhetoric applied to digital storytelling focusing on the strategic use of narratives to maximize specific communicative effects (Iversen). Iversen argues that earlier theories implicitly understood life narratives as stable, autonomous, and mono-perspectival entities, and ignored that in "real, unfolding lives, narratives are often dialogical, multi-perspectival and fragmented." These fragmented experiences are pivotal to digital media because many IDNs are navigated across different platforms and society is increasingly demanding multiple perspectives.

An IDN is "an expressive digital narrative form realised in a system containing potential narratives and experienced through a process that results in products that represent instantiated narratives" (Koenitz 180). The IDN system describes "the digital artefact, as it exists on a digital storage medium combined with the hardware" that contains potential narratives or protostories (Koenitz 133). A protostory functions as a procedural blueprint for the space of potential narratives; it includes the computer program (code and interactive interface) and the "artistic intent that enables a participatory process of instantiation that results in the realization of potential narratives" (Koenitz 133). The process of producing realized narratives requires the user to think about the consequences of their actions on the narrative, assess their level of narrative control, and then execute strategies of interaction (Koenitz 180). The IDN system, process, product, and the related vocabulary "forms the beginning of a more fully developed theory" (Koenitz 184). For the future development of IDN theory, Koenitz et al. highlighted three possible approaches: a pragmatic semiotic approach, an approach examining player emotions, and a medium-centric approach (25-30). The following sociocultural analysis adopts the latter approach to discuss how digital media have impacted the rhetoric of nonfiction IDNs, calling for an expansion of digital rhetoric for future narrative composition. 


\section{The Modes of Persuasion and Digital Narrative Audiences}

The modes of persuasion provide a classical foundation for reflection on the current impacts digital media narratives have on today's audiences/society. There are three modes of persuasion: "The first kind depends on the personal character of the speaker; the second on putting the audience into a certain frame of mind; the third on the proof, or apparent proof, provided by the words of the speech itself" (Aristotle 7). In other words, ethos can be interpreted to refer to the characteristics of the rhetor, pathos to the audience's reception elicited through the delivery techniques, and logos to the logic of arguments or messages. Ethos will be discussed in the context of how digital media has shifted society's perception of the content producer and how audiences have simultaneously become producers. Pathos is considered in the context of how multimodal ${ }^{1}$ content is increasingly being used, and $\log o s$ in terms of multiperspective narratives and transmediality. Finally, the often-neglected kairos-which in ancient Greek meant the "right or opportune moment" (Sheridan, Ridolfo, and Michel 6) - is contextualized within the nature of procedurality or dramatic agency afforded to IDN users.

\section{Ethos: Distrust and the Rise of Vernacular Participatory Culture}

Narratives published in print, video, or radio were historically created using a topdown approach (creator to audience) because not everyone had the financial means and access to the technology and skills required for production. As a result of Web 2.0 technologies, the rise of the bottom-up approach took hold as media production was democratized and the masses were able to use new media technologies to create their own narratives. As Haskins states, "Instead of only official accounts disseminated by mainstream media and the government, all kinds of stories can now become part of an evolving patchwork of public memory" (405). The explosion of user-generated content (UGC) resulted in an increasingly participatory culture where consumers actively participate in the creation and circulation of new content (Jenkins 90). For example, in business the emergence of online word-of-mouth marketing gave rise to social media influencers (members of the public who are paid to promote a brand, product, or services), and in journalism bloggers became "citizen journalists" documenting and publishing real-time events as they occurred. Along with the democratization of content publishing, the value of vernacular narrative increased and put more pressure on producers to establish ethos because of the growing distrust in digital content published by media and other industries. Ethos in a digital context is established or broken through the source (e.g., expertise, skills, motives), which may not be a single rhetor: it could be a brand, company, or community of social media influencers. Middleton, Hess, and Senda-Cook state that rhetorical force/influence is "exerted through the totality of rhetorical experiences that form vernacular communities and (counter) public spheres. Such recognition further emphasizes the active role of the audience in rhetorical practice" (13). The digital turn toward participatory culture has resulted in vernacular narratives that become part of the overall rhetoric. 


\section{Pathos: Multimodality and Continued Growth of New Media Technologies}

Many communications of the past were created in one mode and delivered in one medium, such as speeches delivered orally in-person, texts written on paper, and paintings on canvas. With new media technologies, all these modes can appear in a single medium. For example, digitized paintings, scanned photographs, or novels can be incorporated into one digital interface such as a website, becoming remediations $^{2}$ of their original forms. Digital remediation often has one of two goals: either to erase the presence of the digital medium or to use the digital medium to enhance a communication (Bolter and Grusin 46). Looking at examples of new media, virtual reality tries to immerse the viewer into the digital world to the point where they cannot "feel/see" the digital medium, while digital encyclopedias, on the other hand, use the digital medium to improve upon the printed form by facilitating keyword searches and including other modalities like sound and video to enhance the user's understanding of a concept (Bolter and Grusin 46). Multimodal digital texts have expanded the choices and means for communication and persuasion in different narrative forms. Each technical or digital production decision is also rhetorical, because it has consequences for how a text will be received and used by its intended audience (Sheppard 128). As Kress explains, "There are now choices about how what is to be represented should be represented: in what mode, in what genre, in what ensembles of modes and genres and on what occasions" (117). These choices differ for each IDN genre and result in different impacts on the pathos experienced by audiences. There is a specialization of modalities which may carry one part of a message for which it is best equipped (Kress 117). Therefore, rhetors must consider and know which type of content is best suited for each semiotic mode of communication depending on the desired affect they seek from the audience (Sánchez-Mesa et al. 16). As new media technologies continue to develop, the combination of modalities in a single delivery medium may increase and could lead to new art forms that elicit the emotional responses desired by rhetors from audiences.

\section{Logos: Multi-Perspective Narratives}

Another socio-contextual aspect of digital media's impact on rhetoric is the concept of transmedia narratives and multi-perspectivity. Media scholars have discussed how the age of "old media" was a time of primarily one-way communication and that new media has opened up rhetoric to two-way communication where readers may respond using the same media as the content producer. For example, popular competition shows on television such as America's Got Talent (2006-) or Eurovision Song Contest (1957-) ask for audience participation through voting for their favorite competitors, but fans also produce their own commentary and have discussions on social media. The narrative of a competitor's journey to winning the top prize includes the edited and produced TV show, the results of viewers calling in or voting 
online for their favourites, and the paratexts created by fans and media sources (e.g., newspapers, talk show hosts). In conjunction with the rise in participatory culture, logos is impacted by this cross-media and paratextual content. The rhetoric around a narrative can completely change as a result of participatory culture and the multiple perspectives and opinions available in digital media. What is communicated in the paratext can change the rhetorical impact of the original narrative source for better or for worse and, thus, the public has influence in determining the logos. Paratexts include fan-produced blogs, writings, and other social media content related to, using (i.e., remixing), or inspired by the original source narrative. The internet has produced a "remix culture," which Lessig describes as "using the fruits of someone else's creativity" to produce something new (51). The original narrative producers may choose to directly engage with multiple perspectives by creating a transmedia narrative or by remixing popular paratexts into the "official narrative." The computer "offers us a multidimensional kaleidoscope with which to rearrange the fragments over and over again, and it allows us to shift back and forth between alternate patterns of mosaic organization" (Murray 156-57). Considering this, a narrative may theoretically never come to an end in digital media, since the logos can continually evolve as new perspectives are added.

\section{Kairos: Procedurality and the Ephemeral Situation}

The colloquial phrase "timing is everything" is of high importance in the digital age of real-time information, which raises the rhetorical concept of kairos. Although kairos is complex and resists simple definitions (Sheridan, Ridolfo, and Michel 6), it can be explained as the sum total of contexts-both spatial and temporal-that encompasses the occasion/situation itself, the genre conventions required, and the delivery the audience expects at that time and place (Sheard 291). Kairos contextualizes or situates human activity: "It delimits choices and sets the boundaries of action by supplying the circumstantial (although often assumed universal) criteria or 'codes'-conventions, values, ethics, customs - that guide and confirm decisions and actions" (Sheard 292). Digital media, particularly those distributed on the internet, are global; they traverse space, time, contexts, and cultures, which have different values, ethics, and customs. Furthermore, IDNs are produced as a result of user interaction with spatial-temporal narrative design, rules, and structure. Kairos is "the very source of rhetoric's power to adapt to circumstances" (Sheard 293). Adaptive hypermedia and artificial intelligence are two examples of how IDN products can emerge differently based on user actions with the potential narratives in the system. A large area of adaptive-related research is personalization, which involves studying user preferences, behaviors, and intentions, modelling content, and filtering recommendations that can lead to more desirable experiences for system users (Gao, Liu, and $\mathrm{Wu}$ ). The concept of kairos is an important consideration in nonfiction IDNs, as it "denotes the infinite combinations of consubstantial, scenic elements that exist as potentialities of discursive acts. As such, it can never be 'pinned down' or reduced to a single one of its components" 
(Sheard 306). Serving as a reminder of the numerous factors rhetors do not control but which determine what is rhetorically possible at a given moment, the concept of kairos draws attention to the connection between occasion and audience (Sheridan, Ridolfo, and Michel 7). The current societal context and the impact digital media has on ethos, pathos, logos, and kairos in IDNs thus raises new questions in regard to how digital narratives are produced and analyzed according to the canons of rhetoric.

\section{Applying the Five Canons of Rhetoric to IDN Composition}

The five canons of classical rhetoric are principles that can be reflected upon as new digital narrative genres emerge (e.g., serious games and museum exhibitions), raising new questions within each canon. The classical canons are challenged due to issues such as new terminology, and the ability to apply them has suffered, particularly in the "memory" and "delivery" canons, which have largely been "forgotten" in more recent scholarship (Brooke 29). Brooke argues for renaming and/or revising the canons (rather than replacing them), which would offer new layers of interpretation and amended terminology (43). Reframing the canons within the context of IDN involves the incorporation of narratological and media theories and aims to draw upon rhetoric's long history of practice in order to help formalize the process of analyzing and creating new, purposeful nonfiction IDNs. Eyman summarized how these classical rhetorical principles can be applied to digital practice, and his modifications will be adapted further for the application to nonfiction IDNs. He writes that in digital practice, invention involves searching networks of information using multimodal and multimedia tools; arrangement is manipulating digital media and selecting or remixing ready-made works; style denotes the elements of design (color, interactivity, font choice, etc.); delivery is using systems of distribution; and memory relates to information literacy in terms of knowing how to store, retrieve, and manipulate (digital) information.

The five canons are presented in a series of ordered steps because oral speeches in ancient Greece, and other traditional rhetoric, tended to be for the creation of oneway communications, but digital media necessitates a change in this linear process. The first adaptation of the canons for IDNs involves reframing them into a cyclical, bottom-up approach, with "delivery" considered much earlier in the process, along with "invention," which may be a symbiotic process (see Figure 1). Secondly, "arrangement" is also closely linked to "invention" and "delivery," and these steps are not as definitively separate in digital media. The "style" canon is renamed to "design," which is commonly used across many creative industries producing content in various digital media. The "memory" canon, while keeping some of its original function, is renamed to "updates," as this is a common requirement and term used in reference to digital media. These reframed canons are discussed below in more detail as they apply to IDNs. 


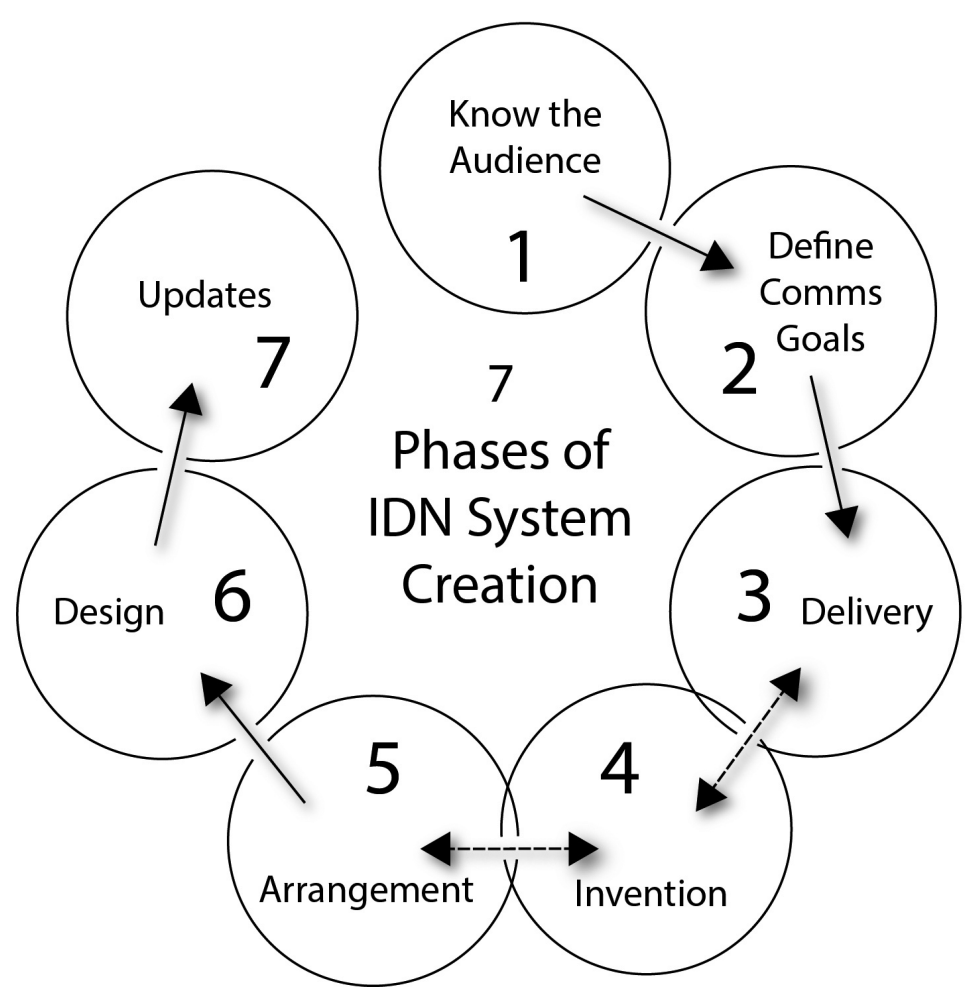

Figure 1. Reframing the Process: Cyclical Digital Rhetorical Canons

\section{Invention: Purpose, Audience, And Content}

Creating IDN systems requires many technical production decisions, which are also rhetorical and have consequences for how the communication will be received and used by the audience. The invention phase for creating a nonfiction IDN system involves four main considerations: (1) the purpose/goals of the narrative or overall desired rhetorical message; (2) who the audience is, because they will determine in part how the rhetoric is received; (3) which content or means of rhetoric are available; and (4) what form or genre the IDN will take. When composing digital rhetoric in general, it is necessary to determine what the communication goals are, who the audience is and their comprehension, and how different multimodal content fits into a digital interface to meet the communication goals (Ridolfo and Hart-Davidson). Firstly, determining the rhetorical goals of developing an IDN will ensure focused decision-making for the rhetorical composition choices. For example, in a serious game called Gaming for Peace (2019), the aim is to simulate real-life situations to 
train peacekeepers to improve gender awareness, cultural awareness, and communications skills. Other examples of rhetorical goals may be to elicit audience empathy or a specific emotional response, to argue a key message, to achieve specific learning outcomes, or to serve as a call to action.

Secondly, to prevent the pitfalls of a top-down approach, the audience should be considered during the invention stage. Researching audience demographics and which digital media they currently use will help ensure their digital literacies will enable them to use the IDN system. This audience research can highlight the user requirements for getting oriented with a new digital form, help tailor the IDN to their preferences (if discoverable), and inform a release or marketing strategy. Existing user-generated content also serves as an important resource for audience insight. Remixes are often UGC that include commentary, opinions, and creative ideas, and they should be gathered and reviewed for inspiration or possible inclusion in an IDN system. Reviewing UGC as a source of "networked information" (Eyman) gives the audience a voice early in the development process and converges content from professional media producers (top-down) and media consumers who are also producing content (bottom-up) in the digital age. Eyman discusses remixing under the arrangement principle of rhetoric, but it should also be considered under the invention principle because the process of remixing is an integral part of the current digital culture and thus needs to be considered when inventing IDN systems. Furthermore, some IDNs have been completely developed as remixes (e.g., transmedia adaptations of classic literature, fan fiction). It is also important to note that once a new IDN is created, it may later be remixed by users: digital media support and encourage participatory culture, and possible future remixes can also be reviewed later in the "update" principle (a reframing of the "memory" canon).

The third consideration in IDN invention is the content, which involves the co-creative process, the affordances of multimodality, and the art (i.e., techne) of persuasion. Many IDNs are created by teams of specialists (e.g., writers, editors, producers, designers) rather than a single person, and managing their involvement and considering what they can offer in terms of content invention adds a new layer of complexity to digital rhetoric invention. The digital medium is inherently multimoal, and the aim of including multimodal content is not to disrupt or disturb the reading experience, but rather to encourage readers to see this content as an integral part of the work and enhance meaning making (Hallet 136). With the continually developing technologies available-such as virtual reality, augmented reality, and mixed reality, among others-content producers must know what type of content is best suited for each semiotic mode of communication (Sánchez-Mesa et al. 16). The art of storytelling is subjective, and a prescriptive, overall rhetorical method is impossible to define for all possible forms of IDN. Thus, the content and available means of persuasion of any IDN will need to be determined by the creators. There is a multitude of established narrative conventions and techniques that IDN inventors can draw upon, such as characters as storytellers, style and tone of voice, and structure/gaps (Phelan 52). The delivery is the next rhetorical canon to be discussed, because it also needs to be considered in parallel with invention. 


\section{Delivery: IDN GenRe AND SOFTWARE}

IDNs can be delivered through digital media or across multiple media (i.e., transmedia). Selecting the genre will help determine which hardware and software are required for IDN system invention. Ryan explains that the "medium imposes its possibilities and limitations on the user" and media are selected "for their affordances, and we work around their limitations, trying to overcome them or to make them irrelevant" (Defining Media 11; emphasis original). An IDN may take full advantage of the medium, ignore the specifics of the medium and use it purely as a transmission channel, fight some of the medium's properties for expressive purposes, or expose latent properties in its medium and expand its expressive potential (13). A nonfiction IDN can achieve stronger rhetoric by taking full advantage of the medium. Technology impacts society in a way that changes "the scale, pace or pattern" of human affairs (McLuhan 7), and the internet has undoubtedly changed the scale, speed, and medium of content delivery. Therefore, the delivery should not only consider the affordances and limitations of each delivery medium, but also whether an IDN should be delivered across different media (i.e., transmedia). Creators need to determine which IDN genre makes sense and the rhetorical goals for each project. Developing an IDN system also involves selecting which software or "authoring tool" to use, a choice which, as McNely and Teston note, can have rhetorical implications. The software can place technological limitations on creative expression and/or provide unforeseen opportunities during the content gathering process. Therefore, the modes, medium, and ability to represent them in the IDN system need to be considered. Many different authoring software exist, each built for a specific purpose, and understanding the affordances and limitations of this software may lead to the exploration of the technical possibilities in the invention phase, or may highlight creative compromises that need to be made because the technology to create the desired rhetoric may not exist or is not accessible/feasible. Research by Shibolet, Knoller, and Koenitz into authoring software development provides more insight into the qualities, purpose of design, and the researchers have recently created a website listing the existing software for reference. Software selection will require individual project-based research to determine the appropriate solutions that allow the communication goals of the specific IDN to be achieved.

\section{Arrangement: Procedural Authorship of Narratological STRUCTURE AND INTERACTIVITY}

Arrangement in classical rhetoric would have involved the formal organization of each part of a speech (Eyman), but in IDNs it is predetermined by the creators and (in some cases) in part by the user, which can lead to new arrangements or emergent narratives with each reading. Eyman refers to rhetorical arrangement as functioning "architecturally" (69), and the term "information architecture" (118) is commonly used in digital media practices such as web design and in transmedia stories like Star Wars, of which George Lucas has been described as the "story architect" (Sánchez- 
Mesa et al. 11). Arrangement of IDNs involves procedural authorship to determine the narrative structure and level of user interactivity. Procedural authorship, Murray explains, includes writing the rules by which the texts appear, writing the texts, and determining the rules for what will happen in response to the participant's actions (152). The IDN arrangement is an important factor in mitigating issues of ludonarrative dissonance, because user interactivity needs to correspond with the narrative. Determining the level of desired user interactivity will inform the narrative structure needed for an IDN.

Ryan defines five levels of interactivity, ranging from low to high, which can be used as a reference for rhetorical analysis and/or creation (175-85). She explains that Level 1 interactivity is low and does not affect the order of the discourse it presents (e.g., many printed novels); Level 2 interactivity has predetermined story content, but the order is variable (e.g., choose-your-own-adventure novels); and in Level 3 interactivity, the user becomes a member of the storyworld and progresses along a fixed storyline controlled by the system (e.g., video games) (176-81). Levels 4 and 5 offer more complex levels of interactivity. Level 4 stories are not predetermined but generated "on the fly out of data that comes in part from the system and in part from the user" (e.g., AI environments) (Ryan 176-81). However, in a Level 4 interactive narrative, the system must be authored such that users respond to affordances built into the system rather than being completely responsible for constructing the story (Ryan 183). In Level 5, the "interactor is not using the system but, rather, modifying it for other users" and this meta-activity involves expanding the possibilities of action offered by the storyworld and would require permitting users access to the system so they can modify it or add to it (Ryan 185). Considering these options, digital culture favors narratives that promote "emergence and self-renewability" or replay value (Ryan 185), which is in part determined by the level of interactivity. Level 1 and 2 interactive narratives have little replay value, Level 3 offers some replay value, Level 4 has relatively high replay value because it provides opportunities for new content creation and alternate endings, while Level 5 allows consumers to become co-authors who can modify and/or add to the narrative. The narrative communication goal(s) and level of desired user agency can inform which level of interaction should be provided. If there is a stronger need to communicate a narrative or message, a lower interactivity level would be provided. If the focus of an IDN is the experience or the communication of a theme (e.g., narrativity), then a higher level of interactivity would be provided.

Once the level of interactivity is determined, the rules for connecting or linking the different "little stories" or "micro narratives" (Ryan, "Modes of Narrativity" 372) of the main plot and multimodal content need to be determined through procedural authorship of a narrative structure. For example, Ryan, among other scholars, has identified some common narrative structures for interactive narratives. Each IDN, depending on the genre, would follow a different narrative structure; thus, the prototype structures as described by Ryan (Narrative as Virtual Reality 2) can be modified as the IDN demands. Procedural authorship involves combining the content gathered into a narrative structure based on the level of interactivity provided, and in turn determines how the narrative emerges. IDNs involve a sense of play, proce- 
dures, and rules, and procedural rhetoric provides a theoretical pillar upon which the IDN design can impact and improve the reception of the overall rhetoric. Bogost's procedural rhetoric, while grounded in video games, can be applied to persuasive processes in IDNs (playableUCSC). Procedural rhetoric is "the practice of using processes persuasively, just as verbal rhetoric is the practice of using oration persuasively and visual rhetoric is the practice of using images persuasively" (Bogost, Persuasive Games 28). IDNs, which include video games as one genre, are procedural systems that "generate behaviors based on rule-based models; they are machines capable of producing many outcomes, each conforming to the same overall guidelines" (Bogost, "Rhetoric of Video Games" 122). The authorship of the IDN involves determining the procedures and rules around how much agency (and/or choice) the audience has about the direction of the narrative path. When the audience interacts with the IDN, they participate in creating rhetoric because their actions impact the narrative that emerges from the IDN system. The procedural rhetoric of the narrative arrangement can be compared to a digital "hands-on" experience where the audience engages with the content by doing.

\section{Design: Interface Design and Genre Conventions}

In classical rhetoric, the style in speeches would involve grammatical correctness, clarity, and drawing upon poetic devices (Eyman). In digital rhetoric, style moves away from language and focuses more on interface design, including options like color, font choice, layout, appropriate use of media, and usability (Eyman). Like invention, design is also artistic and subjective; it involves specialized skills and knowledge, such as design thinking, color theory, and user experience design. The interface design impacts how long a user will spend engaging with an IDN and contributes to their level of immersion. Manovich argues that artists historically made a work within a single medium, so the interface and the work were one in the same, but in new media they are separate, which results in the possibility of creating multiple interfaces for the same material accessed from a database of multimodal material (227). The computer interface is not a neutral transport mechanism, but "acts as a code that carries cultural messages in a variety of media. When you use the Internet, everything you access - texts, music, video, navigable spaces-passes through the interface of the browser" and usually affects the messages transmitted (Manovich 64). If an interface is difficult to navigate, has slow load speeds, or is confusing, a user is likely to leave more quickly than if the experience is intuitive, pleasant, and immersive. The aesthetics need to clearly identify how to navigate through the content, show which options users have for interaction, and instruct users in how to select those options (e.g., clicking a text-based hyperlink, an icon, or an image). Many IDN genres have a single digital interface (e.g., interactive fiction, interactive cinema), but video games often have more than one interface-one interface for the regular game-play mode and another interface to display menu-based information such as the current level, avatar health, and a map of the whole game world, etc. Therefore, depending on the IDN genre, the interface design choices need to be intuitive for the user and could 
also be used to create more meaning, depending on how the multimodal content is deployed and through which mode it is delivered, as determined during invention and arrangement. Many issues impeding rhetorical success are technical, as the user experience is important for a seamless experience; so, considering interface usability and design can make or break an IDN system and the rhetorical reception of the narrative.

\section{UPDATES: CONTENT AND STORAgE}

The rhetorical principle of "memory" has been forgotten more recently, because print and digital technologies diminished the need for memorizing the communication. Eyman argues that memory in the digital medium refers to the digital literacies of knowing how to store, retrieve, and manipulate information (71-72). In addition to these features, IDNs can also be revised or updated based on user feedback. To update means to "make something more modern or suitable for use now by adding new information or changing its design" (Cambridge Dictionary). Updating is a common term associated with digital media. Digital software often requests users to update their software to the latest version, which may include "bug fixes" or increased memory or storage. User testing of digital products often pinpoints technical issues that can be remedied through software updates. IDNs hold immense potential for regular updates in content and functionality. Not all IDNs afford users Level 4 or 5 interactivity, but updates could be user-driven through users' active participation in content editing or creation. On a sociocultural level, the internet presents new challenges for creators who need their work to be memorable, updatable, and relevant in today's rapidly changing digital culture, which demands real-time delivery of information. Instead of developing a single communication and delivering it into the world in a one-to-many sequential manner, a digital work has the potential to be a work in progress. Unlike in other media that largely remain the same after production, there is a cultural expectation that content distributed on the internet will always be up to date. For example, a website with outdated content or design causes visitors to lack trust in the narrative (Alsudani and Casey; Flanagin and Metzger; Robins, Holmes, and Stansbury); similarly, mobile applications often release updates to improve the functionality and/or accuracy of the content. IDN creators need to consider the audience's reception to determine whether the IDN needs to be updated (e.g., to edit or expand its argument), re-released (e.g., to respond to a counter-argument), or even spun off into a new narrative (e.g., to further an argument in a new form). There is an opportunity to create stronger rhetoric through updates, remixing, and/or further response to the audience's reaction and interaction with the text. The "memory" principle, reframed as "updates," refers to a variety of small improvements to ensure the narrative remains memorable with the audience, that the content may be ephemeral and allow for the flexibility of time-dependent delivery, and storage updates in terms of RAM memory or other software requirements do not negatively impact the overall lasting rhetoric. 


\section{Conclusion}

As new media technologies develop and are experimented with, the principles of digital rhetoric combined with narrative theory provide a foundation upon which to create persuasive nonfiction-interactive digital narratives in areas such as history, culture heritage, education, and tourism. Digital media have impacted audiences' perception of ethos, pathos, logos, and kairos, and digital rhetorical theory was expanded to bridge the terminological and practical gap between single-medium communications of the past (e.g., oral, written) and multimodal narratives of the present. These theoretical foundations add to the seldom addressed engagement with nonfiction digital narratives and could aid future creators in considering the impacts of digital media on audience reception and interaction with narrative. Scholars of rhetorical discourse and narratology, media ecology, and the creative industries may use these pillars to consider the sociocultural implications new media has on the creation of rhetoric-focused, nonfiction digital narrative genres.

\section{Endnotes}

1. Multimodality can be defined as "the simultaneous co-deployment of resources within a single communication process for meaning-making purposes” (Francesconi 129).

2. Bolter and Grusin explain, "We call the representation of one medium in another remediation, and we argue that remediation is a defining characteristic of the new digital media" (45; emphasis original).

\section{Works Cited}

Almeida, Andre, and Heitor Alvelos. “An Interactive Documentary Manifesto.” In Joint International Conference on Interactive Digital Storytelling, edited by R. Aylett, M. Y. Lim, S. Louchart, P. Petta, and M. Riedl, 123-28. Berlin and Heidelberg: Springer, 2010.

Alsudani, Farah, and Matthew Casey. "The Effect of Aesthetics on Web Credibility". In Proceedings of the 23rd British HCI Group Annual Conference on People and Computers: Celebrating People and Technology, 512-19. Swinton, UK: British Computer Society, 2009. http://dl.acm. org/citation.cfm?id=1671011.1671077 (accessed 17 May 2021).

Anderson, Eike Falk, Leigh McLoughlin, Fotis Liarokapis, Christopher Peters, Panagiotis Petridis, and Sara de Freitas. "Serious Games in Cultural Heritage." In Proceedings of the 10th International Symposium on Virtual Reality, Archaeology and Cultural Heritage, edited by M. Ashley and F. Liarokapis. 2009.

Andreoli, Roberto, Angela Corolla, Armando Faggiano, Delfina Malandrino, Donato Pirozzi, Mirta Ranaldi, Gianluca Santangelo, and Vittorio Scarano. "A Framework to Design, Develop, and Evaluate Immersive and Collaborative Serious Games in Cultural Heritage.” Journal on Computing and Cultural Heritage (JOCCH) 11.1 (2017): 1-22.

Aristotle. Rhetoric. Translated by W. Ryes Roberts. New York: Cosmino, 2010.

Aston, Judith, and Sandra Gaudenzi. "Interactive Documentary: Setting the Field." Studies in Documentary Film 6.2 (2012): 125-39. 


\section{Nicole Basaraba, Peter Arnds, Jennifer Edmond, and Owen Conlan}

Bogost, Ian. Persuasive Games: The Expressive Power of Videogames. Cambridge, MA: MIT Press, 2007.

- "The Rhetoric of Video Games." In The Ecology of Games: Connecting Youth, Games, and Learning, edited by Katie Salen, 117-40. Cambridge, MA: MIT Press, 2008.

Bolter, David J., and Richard Grusin. Remediation: Understanding New Media. Cambridge, MA: MIT Press, 1999.

Boyle, Casey, James J. Brown, Jr., and Steph Ceraso. "The Digital: Rhetoric Behind and Beyond the Screen." Rhetoric Society Quarterly 48.3 (2018): 251-59.

Brooke, Colin Gifford. Lingua Fracta: Toward a Rhetoric of New Media. Cresskill, NJ: Hampton Press, 2009.

Cambridge Dictionary. “Update.” https://dictionary.cambridge.org/dictionary/english/update (accessed 17 May 2021).

Dow, Steven, Jaemin Lee, Christopher Oezbek, Blair Maclntyre, Jay David Bolter, and Maribeth Gandy. "Exploring Spatial Narratives and Mixed Reality Experiences in Oakland Cemetery." In Proceedings of the 2005 ACM SIGCHI International Conference on Advances in Computer Entertainment Technology, 51-60. 2005. https://dl.acm.org/doi/10.1145/1178477.1178484 (accessed 17 May 2021).

Dufresne, David. Fort McMoney. Digital documentary/video game, 2013.

Eyman, Douglas. Digital Rhetoric: Theory, Method, Practice. Ann Arbor: Univ. of Michigan Press, 2015.

Fanini, Bruno, and Alfonsina Pagano. "Interface Design for Serious Game Visual Strategies: The Case Study of 'Imago Bononiae." Paper presented at Digital Heritage, 28 September-2 October 2015. https://www.researchgate.net/publication/287632413_Interface_Design_for_Serious_ Game_Visual_Strategies_-_The_Case_Study_of_Imago_Bononiae (accessed 17 May 2021).

Flanagin, Andrew J, and Miriam J. Metzger. "The Role of Site Features, User Attributes, and Information Verification Behaviors on the Perceived Credibility of Web-based Information." New Media and Society 9.2 (2007): 319-42.

Francesconi, Sabrina. Reading Tourism Texts: A Multimodal Analysis. Bristol: Channel View Publications, 2014.

Freeman, Matthew. "Small Change-Big Difference: Tracking The Transmediality of Red Nose Day." Journal of European Television History and Culture 5.10 (2016): 1-10.

Gaming for Peace. GAP Project, 2019. https://gap-project.eu/ (accessed 17 May 2021).

Gao, Min, Kecheng Liu, and Zhongfu Wu. "Personalisation in Web Computing and Informatics: Theories, Techniques, Applications, and Future Research". Information Systems Frontiers 12.5 (2010): 607-29.

Haahr, Mads. "Literary Play: Locative Game Mechanics and Narrative Techniques for Cultural Heritage.” In Joint International Conference on Serious Games 2015, 114-19. Cham: Springer, 2015.

Hallet, Wolfgang. "The Multimodal Novel: The Integration of Modes and Media in Novelistic Narration". In Narratology in the Age of Cross-Disciplinary Narrative Research, edited by Sandra Heinen and Roy Sommer, 129-53. Berlin: De Gruyter, 2009.

Haskins, Ekaterina. "Between Archive and Participation: Public Memory in a Digital Age." Rhetoric Society Quarterly 37.4 (2007): 401-22.

Herman, David. Story Logic: Problems and Possibilities of Narrative. Lincoln: Univ. of Nebraska Press, 2002. 
Iverson, Stefan. "Narratives in Rhetorical Discourse.” In The Living Handbook of Narratology, 31 January 2014. https://www.lhn.uni-hamburg.de/node/117.html (accessed 17 May 2021).

Jenkins, Henry. "The Cultural Logic of Media Convergence.” International Journal of Cultural Studies 7.1 (2006): 33-43.

Kenderdine, Sarah. mARChive: Sculpting Museum Victoria's Collections. Video exhibition, 2014. http://mw2014.museumsandtheweb.com/paper/marchive-sculpting-museum-victorias-collections/ (accessed 17 May 2021).

Kidd, Jenny. Museums in the New Mediascape: Transmedia, Participation, Ethics. Farnham, UK: Ashgate Publishing, 2014.

Knoller, Noam. “Authoring Tools for Interactive Digital Narrative-An Online Resource.” 9 January 2019. http://interactivenarrativedesign.org/authoringtools/ (accessed 17 May 2021).

Koenitz, Hartmut. “Towards a Theoretical Framework for Interactive Digital Narrative.” In Third Joint Conference on Interactive Digital Storytelling, ICIDS 2010, edited by Ruth Aylett, Mei Yii Lim, Sandy Louchart, Paolo Petta, and Mark Riedl, 176-85. Edinburgh: Springer, 2010.

Koenitz Harmut, Gabriele Ferri, Mads Haahr, Diğdem Sezen, and Tonguç Ibrahim Sezen. "Introduction: Perspectives on Interactive Digital Narrative.” In Interactive Digital Narrative: History, Theory and Practice, edited by Hartmut Koenitz, Gabriele Ferri, Mads Haahr, Diğdem Sezen, and Tonguç Ibrahim Sezen, 1-8. New York: Routledge, 2015.

Koenitz Hartmut, Mads Haahr, Gabriele Ferri, and Tongue Ibrahim Seen. "First Steps Towards a Unified Theory for Interactive Digital Narrative." In Transactions on Edutainment X, edited by Zhigeng Pan, Adrian David Cheok, Wolfgang Muller, Ido Iurgel, Paolo Petta, and Bodo Urban, 20-34. Berlin: Springer, 2013.

Kress, Gunther. Literacy in the New Media Age. New York: Routledge, 2003.

Laurel, Brenda. Computers as Theatre. Boston: Addison-Wesley, 2013.

Lessig, Lawrence. “The People Own Ideas!: New Technologies Are Forcing Us to Make Important Choices about How We Use Books, Music, Software, and Other Cultural Products. Do We Want Them to Be Free-Or Not?" MIT Technology Review 108.6 (2005): 46-53.

Losh, Elizabeth Matthews. Virtualpolitik: An Electronic History of Government Media-making in a Time of War, Scandal, Disaster, Miscommunication, and Mistakes. Cambridge, MA: MIT Press, 2009.

Manovich, Lev. The Language of New Media. Cambridge, MA: MIT Press, 2001.

McKercher, Bob, and Hilary Du Cros. “Testing a Cultural Tourism Typology.” International Journal of Tourism Research 5.1 (2003): 45-58.

McLuhan, Marshall. Understanding Media: The Extensions of Man. Cambridge, MA: MIT Press, 1964.

McNely, Brian and Christa Teston. "Tactical and Strategic: Qualitative Approaches to the Digital Humanities." In Rhetoric and the Digital Humanities, edited by Jim Ridolfo and William Hart-Davidson, 111-26. Chicago: Univ. of Chicago Press, 2014.

Mendes, Jeremy, and Leanna Allison. Bear 71. Digital documentary, 2012. http://bear71.nfb.ca/\#/ bear71 (accessed 17 May 2021).

Middleton, Michael, Aaron Hess, Danielle Endres, and Samantha Senda-Cook. Participatory Critical Rhetoric: Theoretical and Methodological Foundations for Studying Rhetoric in Situ. London: Lexington Books, 2015. 


\section{Nicole Basaraba, Peter Arnds, Jennifer Edmond, and Owen Conlan}

Monfort, Nicholas. "Forward". In Interactive Digital Narrative: History, Theory and Practice, edited by Hartmut Koenitz, Gabriele Ferri, Mads Haahr, Diğdem Sezen, and Tonguç Ibrahim Sezen, ix-xiii. New York: Routledge, 2015.

Mortara, Michela, Chiara Eva Catalano, Francesco Bellotti, Giusy Fiucci, Minica Houry-Panchetti, and Panagiotis Petridis. "Learning Cultural Heritage by Serious Games." Journal of Cultural Heritage 15.3 (2014): 318-25.

Murray, Janet. Hamlet on the Holodeck: The Future of Narrative in Cyberspace. New York: The Free Press, 1997.

Nash, Kate. "I-Docs and the Documentary Tradition: Exploring Questions of Citizenship." In I-Docs: The Evolving Practices of Interactive Documentary, edited by Judith Aston, Sandra Gaudenzi, and Mandy Rose, 9-25. New York: Columbia Univ. Press, 2017.

Nielsen, Henrik Skov, James Phelan, and Richard Walsh. "Fictionality as Rhetoric: A Response to Paul Dawson.” Narrative 23.1 (2015): 101-11.

—_. "Ten Theses about Fictionality." Narrative 23.1 (2015): 61-73.

O’Flynn, Siobhan. “Documentary's Metamorphic Form: Webdoc, Interactive, Transmedia, Participatory and Beyond." Studies in Documentary Film 6.2 (2012): 141-57.

Paterson, Natasa, Gavin Kearney, Katsiaryna Naliuka, Tara Carrigy, Mads Haahr, and Fionnuala Conway. "Viking Ghost Hunt: Creating Engaging Sound Design for Location-Aware Applications." International Journal of Arts and Technology 6.1 (2013): 61-82.

Peters, John Durham. The Marvelous Clouds: Toward a Philosophy of Elemental Media. Chicago: Univ. of Chicago Press, 2015.

Pfister, Damien Smith. Networked Media, Networked Rhetorics: Attention and Deliberation in the Early Blogosphere (10). University Park, PA: Penn State Univ. Press, 2014.

Phelan, James. "Voice, Tone, and the Rhetoric of Narrative Communication." Language and Literature 23.1 (2014): 49-60.

Porter, James E., and Patricia A. Sullivan. "Repetition and the Rhetoric of Visual Design." Advances in Discourse Processes 48 (1994): 114.

playableUCSC. "Ian Bogost_-Procedural Rhetoric (Media Systems \#7).” YouTube Video, 30:46, 24 September 2013. https://www.youtube.com/watch?v=VFaqguc_uNk (accessed 17 May 2021).

Ridolfo, Jim, and William Hart-Davidson, eds. Rhetoric and the Digital Humanities. Chicago: Univ. of Chicago Press, 2014.

Riedl, Mark O., and Vadim Bulitko. "Interactive Narrative: An Intelligent Systems Approach.” AI Magazine 34.1 (2013): 67-77.

Robins, David, Jason Holmes, and Mary Stansbury. "Consumer Health Information on the Web: The Relationship of Visual Design and Perceptions of Credibility." Journal of the American Society for Information Science and Technology 61.1 (2010): 13-29.

Ryan, Marie-Laure. Defining Media from the Perspective of Narratology. Unpublished manuscript (n.d.). http://pure.au.dk/portal/files/7562/M-L_Ryans_paper.pdf(accessed 17 May 2021).

- "The Modes of Narrativity and their Visual Metaphors." Style 26.3 (1992): 368-87.

- Narrative as Virtual Reality 2: Revisiting Immersion and Interactivity in Literature and Electronic Media. Baltimore: Johns Hopkins Univ. Press, 2015.

"Toward a Definition of Narrative." In The Cambridge Companion to Narrative, edited by David Herman, 22-35. New York: Cambridge Univ. Press, 2007. 
Sánchez-Mesa, Domingo, Espen Aarseth, Robert Pratten, and Carlos Scolari. "Transmedia (Storytelling?): A Polyphonic Critical Review." Artnodes: E-Journal on Art, Science and Technology 18 (2016): 8-19.

Sheard, Cynthia Miecznikowski. "Kairos and Kenneth Burke's Psychology of Political and Social Communication." College English 55.3 (1993): 291-310.

Sheldon, Elaine McMillion. Hollow. Digital documentary, 2013. http://www.hollowdocumentary. com/ (accessed 17 May 2021).

Sheppard, Jennifer. "The Rhetorical Work of Multimedia Production Practices: It's More than Just Technical Skill.” Computers and Composition 26.2 (2009): 122-31.

Sheridan, David M., Jim Ridolfo, and Anthony J. Michel. The Available Means of Persuasion: Mapping a Theory and Pedagogy of Multimodal Public Rhetoric. Anderson, SC: Parlor Press, 2012.

Shibolet, Yotam, Noam Knoller, and Hartmut Koenitz. "A Framework for Classifying and Describing Authoring Tools for Interactive Digital Narrative.” In Interactive Storytelling: 11th International Conference on Interactive Digital Storytelling, 523-33. Cham: Springer, 2018.

Styliani, Sylaiou, Liarokapis Fotis, Kotsakis Kostas, and Patias Petros. "Virtual Museums: A Survey and Some Issues for Consideration.” Journal of Cultural Heritage 10.4 (2009): 520-28.

Szalat, Alex, Joel Ronez, and Susanna Lotz. Gaza/Sderot, Pre-War Chronicles. Digital documentary, 2008. https://www.arte.tv/sites/webproductions/en/gaza-sderot/ (accessed 17 May 2021).

University of Reading. Virtual Rome. Digital gallery. https://research.reading.ac.uk/virtualrome/ (accessed 17 May 2021).

Xu, Feifei, Dimitrios Buhalis, and Jessika Weber. "Serious Games and the Gamification of Tourism." Tourism Management 60 (2017): 244-56.

Zappen, James P. "Digital Rhetoric: Toward an Integrated Theory.” Technical Communication Quarterly 14.3 (2005): 319-25. 